\title{
Uma análise de um jogo educacional sob a ótica do Pensamento Computacional*
}

\author{
Braz Araujo da Silva Junior ${ }^{1}$, Simone André da Costa Cavalheiro ${ }^{1}$, Luciana Foss ${ }^{1}$ \\ ${ }^{1}$ Programa de Pós-Graduação em Computação - Universidade Federal de Pelotas \\ CEP 96.010-610 - Pelotas - RS - Brazil \\ \{badsjunior, simone.costa, lfoss\}@inf.ufpel.edu.br
}

\begin{abstract}
This paper presents an educational game, its expansions, its application and evaluation, from a Computational Thinking perspective. For this, the game elements are related to a set of skills which are part of the Computational Thinking. We conclude that the game has a significant relationship, especially with the skills: data collection and analysis; and algorythms and procedures.
\end{abstract}

Resumo. Este artigo apresenta um jogo educacional, suas extensões, aplicação $e$ avaliação sob a perspectiva do Pensamento Computacional. Para isto são relacionados os elementos do jogo a um grupo de habilidades consideradas parte do Pensamento Computacional. Conclui-se que o jogo possui relações significativas, principalmente com as habilidades de: coleta e análise de dados; e algoritmos e procedimentos.

\section{Introdução}

Desde que [Wing 2006] levantou a discussão acerca do Pensamento Computacional (PC), o tema tem motivado diversos esforços na educação. O conceito se refere a um conjunto de habilidades que auxiliam no processo de resolução de problemas. Muitas destas habilidades acabam sendo desenvolvidas por profissionais da computação. Porém, ao identificar a sua generalidade, percebeu-se a importância de promovê-las de maneira indiscriminada, não somente para os que seguirão carreira na área da computação.

Para que o PC seja desenvolvido de maneira ampla e eficiente é importante que o processo seja iniciado desde os primeiros anos de aprendizado [Barr and Stephenson 2011]. Assim, a educação básica (também chamada de K-12), torna-se alvo importante de cursos para o desenvolvimento do PC. Muitos esforços, de diferentes naturezas, têm sido realizados a fim de viabilizar o desenvolvimento destas habilidades, como mostram algumas revisões sistemáticas [Bordini et al. 2017, Avila et al. 2017]. Os esforços incluem diferentes abordagens, como: robótica [Costella et al. 2017]; jogos digitais [Pinho et al. 2016]; aplicativos [Pessoa et al. 2017]; atividades [Andrade et al. 2013]; e jogos não-digitais [Brown et al. 2010].

Os jogos possuem um apelo especial entre o público mais jovem e têm potencial para manter os alunos em estado de fluxo, onde sua dedicação à atividade

* O presente trabalho foi realizado com apoio da Coordenação de Aperfeiçoamento de Pessoal de Nível Superior - Brasil (CAPES) - Código de Financiamento 001. Projeto realizado com o apoio da PREC e PRPPG / UFPel. 
VII Congresso Brasileiro de Informática na Educação (CBIE 2018)

Anais do XXIX Simpósio Brasileiro de Informática na Educação (SBIE 2018)

é maximizada [Garris et al. 2002]. O estado de fluxo é mantido quando a oportunidade de ação do indivíduo está em equilíbrio com a sua capacidade de ação [Nakamura and Csikszentmihalyi 2009]. Isto é, quando o indivíduo é tão desafiado quanto é capaz de responder aos desafios. O desequilíbrio traz a frustração: por tédio se a relação desafio por capacidade for muito baixa; ou por impotência se for muito alta.

Um exemplo de jogo educacional é "A Última Árvore" [Silva Junior et al. 2017a], um jogo que explora as relações de um formalismo matemático intuitivo, a gramática de grafos (GG), com habilidades do PC. Este recurso didático foi criado por meio de um processo que considera aspectos do design instrucional e de jogos, (o processo ENgAGED [Battistella and von Wangenheim 2016]). Cabe destacar, que esta fundamentação teórica diferencia-o de grande parte das propostas existentes na literatura. Uma análise de 107 jogos realizada em [Battistela et al. 2014] observou que apenas 6 deles expuseram um processo de desenvolvimento.

Considerando que o recurso didático se propõe a desenvolver habilidades do PC, é essencial que as relações do jogo com tais habilidades sejam discutidas. Este artigo traz esta discussão. Para possibilitá-la, são relacionadas as características, jogabilidade e mecânicas do jogo e extensões às habilidades do PC. Uma aplicação piloto do jogo, com pré- e pós- testes também é reportada sob a ótica do PC.

O artigo está organizado como segue. A seção 2 apresenta uma definição operacional do termo PC e o conceito das habilidades que são relacionadas no artigo. A seção 3 apresenta o jogo "A Última Árvore" e sua relação com o PC. Na seção 4 são descritas as extensões do jogo e suas contribuições para o desenvolvimento do PC. Na seção 5 é discutido o teste aplicado, bem como a relação dele com o PC. A seção 6 relata a performance dos alunos durante a aplicação piloto, analisando-a com base no PC. A seção 7 conclui o artigo com uma visão geral sobre o jogo considerando o PC.

\section{Pensamento Computacional}

Neste artigo explora-se a seguinte definição operacional de Pensamento Computacional:

Definição 1 (Pensamento Computacional [CSTA et al. 2009]) Um processo de resolução de problemas que inclui (mas não é limitado a) as seguintes características: formular problemas de uma maneira que nos permita usar um computador ou outras ferramentas para ajudar a resolvê-los; organizar e analisar dados logicamente; representar dados através de abstrações, como modelos e simulações; automatizar soluções através do pensamento algorítmico (uma série de passos ordenados); identificar, analisar e implementar possíveis soluções com o objetivo de alcançar a mais eficiente e efetiva combinação de passos e recursos; e generalizar e transferir este processo de solução de problemas para uma ampla variedade de problemas. Estas competências são sustentadas e aprimoradas por um número de atitudes ou disposições que são dimensões essenciais do PC. Estas atitudes ou disposições incluem: confiança ao lidar com complexidade; persistência ao trabalhar com problemas difíceis; tolerância à ambiguidade; a habilidade de lidar com problemas em aberto; e a habilidade de se comunicar e trabalhar com outros para alcançar uma solução ou objetivo em comum.

Com base nesta definição e no quadro de habilidades sugerido no mesmo material [CSTA et al. 2009], para estabelecer as relações do jogo com o PC considera-se como integrantes do PC as seguintes habilidades: 
VII Congresso Brasileiro de Informática na Educação (CBIE 2018)

Anais do XXIX Simpósio Brasileiro de Informática na Educação (SBIE 2018)

- Coleta e Análise de Dados: processo de coletar informação apropriadamente, a atribuição de sentido aos dados, o reconhecimento de padrões e a extração de conclusões.

- Representação de Dados: apresentação e organização dos dados em grafos, quadros, palavras ou imagens apropriadas.

- Decomposição de Problemas: quebra de tarefas em partes menores e mais manejáveis.

- Abstração: redução de complexidade para trabalhar com uma ideia principal simplificada.

- Algoritmos e Procedimentos: série de passos ordenados seguidos para resolver um problema ou alcançar algum fim.

- Simulação: representação ou modelo de um processo. Simulação também envolve execução de experimentos utilizando modelos.

- Paralelismo: organização de recursos para executar tarefas simultaneamente para alcançar um objetivo em comum.

- Generalização: criação de modelos ou processos genéricos, que reúnem similaridades e padrões a fim de ampliar ou simplificar sua utilização.

- Otimização: análise dos recursos e custos visando maximizar eficiência.

\section{O Jogo}

O recurso didático "A Última Árvore" é um jogo de tabuleiro, de estratégia baseada em turnos, onde os jogadores manipulam uma GG para fazer animais restaurarem uma floresta destruída [Silva Junior et al. 2017a]. O modelo GG descreve o estado de um sistema utilizando um grafo, composto por: um conjunto de vértices; e um conjunto de arestas (relacionamentos entre vértices). Este sistema pode ter seu estado alterado, e estas alterações são definidas por regras. Basicamente, uma regra é definida por [Ribeiro 2000]: dois grafos, denominados lado esquerdo (condição) e lado direito (consequência) da regra; e um mapeamento entre eles, o qual especifica os elementos a serem preservados, criados ou deletados. Para aplicar uma regra é necessário encontrar um match, isto é, um mapeamento entre grafos que indentifica uma ocorrência do lado esquerdo da regra no grafo-estado, o qual será alterado pela regra. A aplicação da regra dá origem a um novo grafo-estado substituindo a ocorrência do lado esquerdo (definida pelo match) pelo grafo do lado direito da regra.

Na versão básica do jogo, o tabuleiro e as cartas compõem um grafo-estado com 4 animais, 5 blocos de terra e recursos (frutas, sementes, plantas e árvores) que podem ser criados ou consumidos ao longo do jogo. No começo da partida cada jogador sorteia um objetivo diferente descrito por uma carta, como a ilustrada na esquerda da Figura 1. Então cada jogador realiza uma ação e passa a vez para o próximo, até que alguém atinja seu objetivo e vença o jogo. As ações possíveis consomem ou requerem recursos do jogo para a criação de novos recursos em um ciclo, ilustrado na direita da Figura 1.

Há 6 ações possíveis no jogo: Mover, para movimentar animais de um bloco de terra para outro; Colher, para adquirir frutas a partir de árvores; Plantar, para criar sementes consumindo frutas; Regar, para criar plantas consumindo sementes; Adubar, para criar árvores consumindo plantas e frutas; e Comer, para consumir frutas. Estas ações são apresentadas no formato de regras da GG, onde o grafo do lado esquerdo representa a condição e o do lado direito a consequência da aplicação das regras. A Figura 2 
VII Congresso Brasileiro de Informática na Educação (CBIE 2018)

Anais do XXIX Simpósio Brasileiro de Informática na Educação (SBIE 2018)
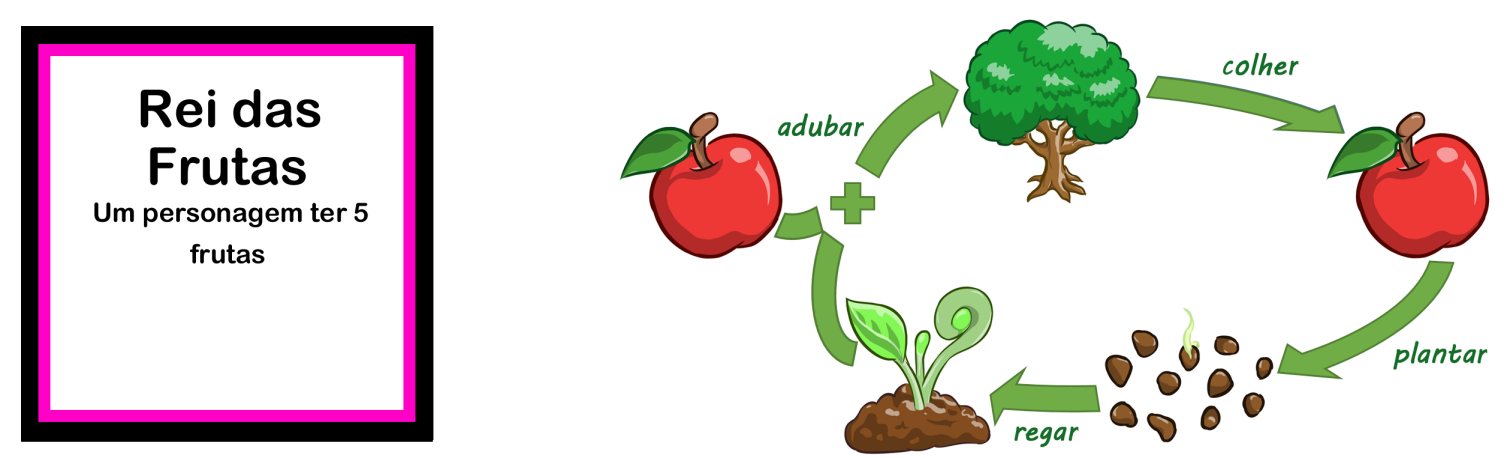

Figura 1. Carta de objetivo (à esquerda) e ciclo dos recursos (à direita).

ilustra as regras: Mover, descrevendo que SE um animal está no bloco de terra pos Atual que possui caminho para outro bloco de terra posAdj, ENTÃO após a aplicação desta regra ele passará a estar no bloco de terra posAdj; e Colher, descrevendo que SE um animal está em um bloco de terra com uma árvore, ENTÃO após a aplicação desta regra ele continuará no bloco, mas também terá uma fruta.
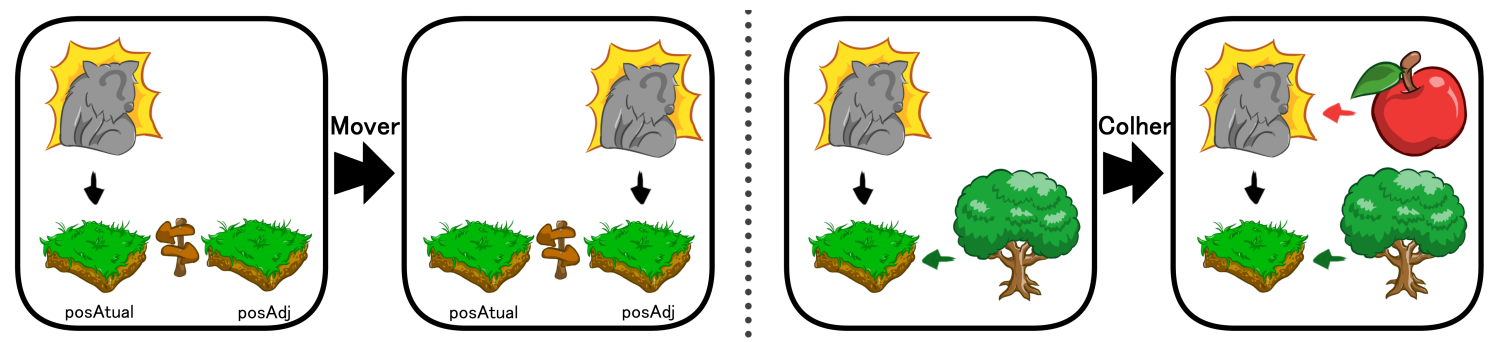

Figura 2. Ações (regras) mover e colher.

Através destas ações, os jogadores devem atingir uma combinação específica destes recursos, definida pela carta de objetivo sorteada no início da partida. Em [Silva Junior et al. 2017a] é apresentada a especificação do jogo original, sua metodologia de desenvolvimento, bem como algumas relações do formalismo GG com o PC. Neste artigo a relação com o PC é analisada considerando as características dos elementos do jogo e suas mecânicas. A coluna "Versão Básica" da Tabela 2 especifica como as habilidades do PC são exploradas no jogo em sua versão básica.

\section{Extensões}

Após a concepção de sua versão básica ${ }^{1}$, extensões do jogo foram propostas, incorporando novos elementos das gramáticas de grafos. A primeira extensão ${ }^{2}$ adicionou as condições negativas de aplicação (NACs, do inglês Negative Application Condition) [Silva Junior et al. 2017b]. Elas são condições adicionais para as ações do jogo, representando proibições, situações onde as ações não podem ser realizadas mesmo que um match seja encontrado. A extensão inseriu diversos novos elementos: 4 novos vértices (o caçador, os namorados, os turistas e a cidade); arestas indicando posição de cada um

\footnotetext{
${ }^{1}$ Para o download da versão básica do jogo acesse https : / / goo . gl / ULG8kJ

${ }^{2}$ Para o download da primeira versão estendida do jogo acesse https : / / goo . gl / yuUsPq
} 
VII Congresso Brasileiro de Informática na Educação (CBIE 2018)

Anais do XXIX Simpósio Brasileiro de Informática na Educação (SBIE 2018)

dos três primeiros novos vértices; 6 novas regras (de movimentação dos novos vértices); e 4 NACs.

Os novos personagens são humanos: o caçador, que impede a movimentação dos animais; os namorados, que impedem a colheita de frutas; e os turistas, que impedem a plantação de sementes. Estes impedimentos são definidos por 4 NACs: $N_{0}$, proíbe a aplicação da regra Mover caso exista um caçador no bloco de terra $\operatorname{pos} A d j ; N_{1}$, proíbe a aplicação da regra Mover caso exista um caçador no bloco de terra pos Atual; $N_{2}$, proíbe a aplicação da regra Colher caso os namorados estejam no bloco de terra; e $N_{3}$, proíbe a aplicação da regra Plantar caso os turistas estejam no bloco de terra. As 6 novas regras movimentam os humanos: Caçar move o caçador da cidade para um bloco de terra; FimDeTemporada move o caçador de um bloco de terra para a cidade; Namorar move os namorados da cidade para um bloco de terra; FimDeNamoro move os namorados de um bloco de terra para a cidade; Acampar move os turistas da cidade para um bloco de terra; e FimDeFérias move os turistas de um bloco de terra para a cidade.

A Figura 3 ilustra as NACs $N_{0}$ e $N_{1}$, sobre a regra Mover, que passa a descrever que: SE um animal está no bloco de terra pos Atual que possui caminho para outro bloco de terra posAdj E SE NÃO há um caçador no bloco de terra pos Adj NEM no bloco de terra posAtual, ENTÃO após a aplicação desta regra, ele estará no bloco de terra pos $A d j$.
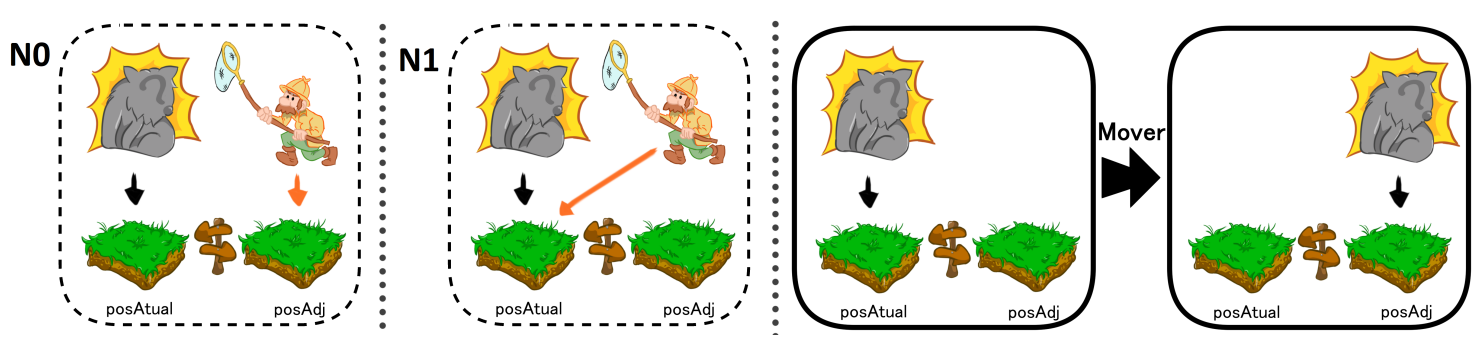

Figura 3. A regra mover com NACs na versão estendida.

Desde a versão básica os jogadores já tinham que lidar com a interferência dos demais, que podiam atrapalhar seus algoritmos e estratégias. Mas a extensão traz a possibilidade de impedir ações sem consumir recursos, apenas movimentando os humanos. Há um aprofundamento estratégico do jogo como um todo, oferecendo novas estratégias para os jogadores adaptarem aos seus estilos e objetivos. A coluna "Primeira Extensão: NACs" da Tabela 2 especifica como as habilidades do PC são exploradas nesta extensão.

Uma segunda extensão ${ }^{3}$ introduz o conceito de atributos nas GGs. Ela converte alguns dos elementos do jogo em atributos, as relações, ações e mecânicas do jogo permanecem as mesmas, mas a representação é alterada. Com os atributos o jogo passa a ter um caráter mais algébrico, colocando os jogadores em contato com números, variáveis e inequações. Por exemplo: na versão básica, para representar que um animal tinha 5 frutas, ele teria que ter 5 cartas de fruta empilhadas; com atributos, essa representação é dada por uma carta com o número 5. Assim, os jogadores precisam fazer incrementos, decrementos e contas simples em suas jogadas, alterando as cartas de número nos lugares indicados. Por isto, o tabuleiro (Figura 4) e as cartas do jogo mudaram significativamente nesta versão. Agora o tabuleiro conta com espaços marcados para cada atributo: frutas

\footnotetext{
${ }^{3}$ Para o download da segunda versão estendida do jogo acesse https : / / goo.gl/KXvHxH
} 
VII Congresso Brasileiro de Informática na Educação (CBIE 2018)

Anais do XXIX Simpósio Brasileiro de Informática na Educação (SBIE 2018)

para cada animal na parte superior; e sementes, plantas e árvores para cada bloco de terra na parte inferior. As ações nesta versão seguem sendo representadas por regras de uma gramática de grafos, porém, incluem atributos. Os atributos nas condições das regras (lado esquerdo) são variáveis representadas por ilustrações. Nas consequências (lado direito) são expressões envolvendo as variáveis, números e operadores. Além disso, abaixo da seta central da regra, há inequações que impõem condições sobre as variáveis usadas em seu lado esquerdo. Por exemplo, veja na Figura 4 a regra Colher, ela representa que: SE há um animal com $f$ frutas em um lugar com $a$ árvores, tal que $a>0$, ENTÃO após a aplicação desta regra este animal terá $g=f+1$ frutas e continuará no lugar com $a$ árvores. Onde $f$ e $a$ são variáveis representadas por ilustrações de frutas e árvores.

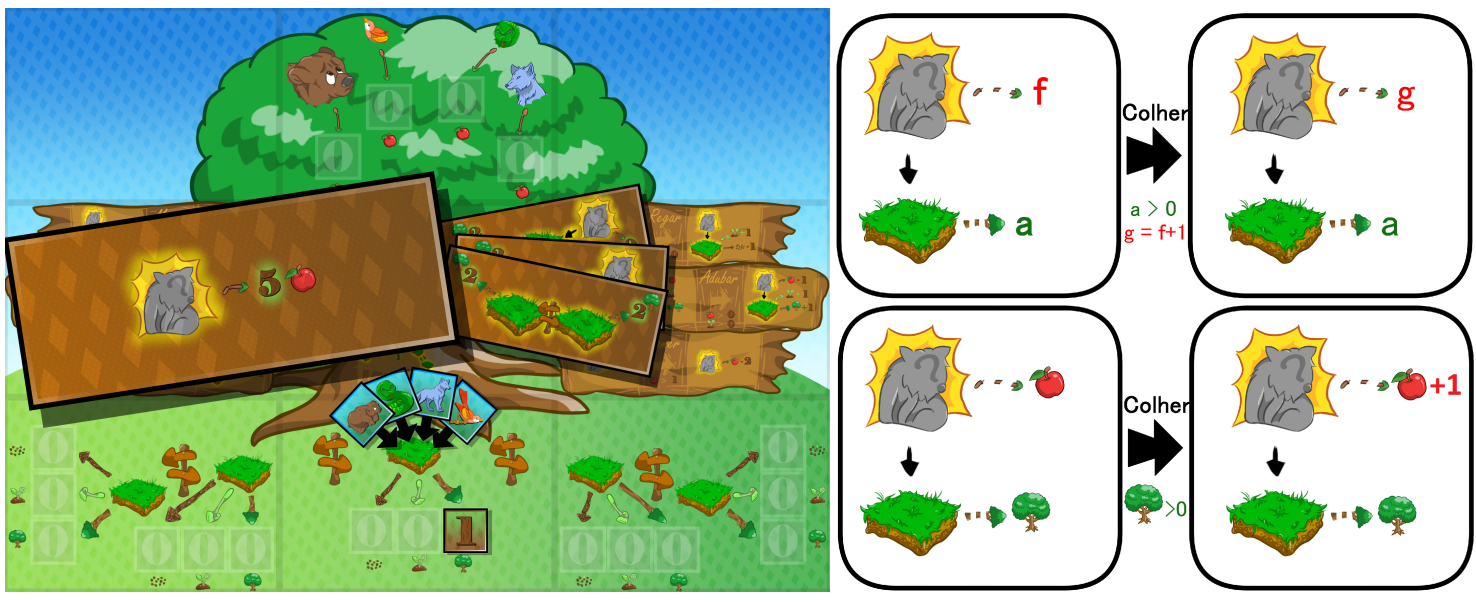

Figura 4. Tabuleiro e cartas (à esquerda) e a regra Colher (à direita

As cartas de objetivo foram alteradas nesta versão e as informações textuais foram substituídas por grafos (com atributos). Algumas delas estão ilustradas à frente do tabuleiro (Figura 4), na parte central. Por exemplo, o objetivo da versão básica ilustrado na Figura 1 foi substituído pela carta em destaque á esquerda no tabuleiro da Figura 4. Os atributos permitem principalmente estimular habilidades matemáticas, conferindo uma característica interdisciplinar ao jogo. Mas também possuem alguns impactos nas habilidades do PC, descritos na coluna "Segunda Extensão: Atributos" da Tabela 2.

\section{Teste de Avaliação}

Para aplicar o jogo e avaliar o desempenho dos jogadores, foi desenvolvido um teste ${ }^{4}$ para ser realizado antes e depois do jogo. Ele foi criado com perguntas direcionadas para avaliar competências específicas das GGs que são consideradas fundamentais para jogar "A Última Árvore": identificar matches; aplicar regras; e lidar com atributos. O teste aborda a história dos três porquinhos. As questões, que contam a história, são classificadas de acordo com as competências que abordam: Q1 match; Q2 aplicação; Q3 match; Q4 aplicação; Q5 atributos; Q6 match e atributos; Q7 aplicação e atributos; e Q8 match e atributos. As relações de atributos com o PC foram delineadas na coluna "Segunda Extensão: Atributos" da Tabela 2, as demais competências abordadas pelo teste são analisadas a seguir.

\footnotetext{
${ }^{4}$ Para o download do teste de gramática de grafos, acesse https://goo.gl/g7xDyn
} 
VII Congresso Brasileiro de Informática na Educação (CBIE 2018)

Anais do XXIX Simpósio Brasileiro de Informática na Educação (SBIE 2018)

Match Intrinsecamente relacionado à coleta e análise de dados, a habilidade de encontrar os elementos de um lado esquerdo em um grafo alvo corretamente pode envolver decomposição de problemas. Ainda que o lado esquerdo de uma regra não possua muitos elementos e relações, é natural que as pessoas, ao buscarem um match, se concentrem em encontrar primeiro uma parte ou até um único elemento, para depois encontrar o todo. Isto envolve um processo de decomposição. Além disso, estratégias como algoritmos e procedimentos tendem a ser desenvolvidas para completar o processo de aplicação de uma regra. Principalmente ao considerar atributos, que também precisam ser mapeados pelo match. Um algoritmo usual de ser aplicado é o de primeiro encontrar o elemento mais raro, depois os que se relacionam à ele e por último identificar os atributos. Ademais, a identificação de diversos matches em uma instância do jogo, permite compreender o conceito de generalização na especificação das regras.

Aplicação Aqui considera-se como "aplicação" a habilidade de compreender e executar as alterações que uma regra provoca ao ser aplicada, não incluindo a busca por um match. No jogo, relaciona-se fortemente à representação de dados, pois os jogadores devem representar manualmente (utilizando as cartas e o tabuleiro) a alteração provocada. A coleta e análise de dados é essencial para determinar quais elementos são criados, deletados ou preservados pela aplicação. A aplicação é o que torna o sistema dinâmico, simulando eventos, ações ou acontecimentos.

\section{Resultados de uma Aplicação Piloto}

Para testar a viabilidade da utilização da ferramenta em sala de aula, aplicou-se o jogo a uma turma do sexto ano de uma escola municipal de Pelotas, E.M. Ferreira Viana. Em um primeiro dia, aplicou-se o teste de GG à toda a sala, 16 alunos, cumprindo a função de pré-teste. Em um segundo dia, os alunos foram chamados em quatro grupos de quatro jogadores. Cada grupo era apresentado ao jogo, jogava uma partida e realizava o teste novamente, como pós-teste. Devido ao comportamento indesejável, com muito desinteresse e dispersão de um dos grupos, pouco pôde-se perceber de sua partida, portanto ele foi excluído da análise. Como relato de experiência, os grupos tiveram comportamentos bastante característicos tanto no pré- e pós-teste quanto nas partidas, classificados em:

Grupo azul: membros com posturas diferentes, mas mantiveram a nota entre os testes Grupo amarelo: apresentou muita dificuldade na compreensão ao jogar, porém estavam interessados e se esforçaram para cumprir as atividades;

Grupo verde: teve interesse desde o pré-teste, tiveram facilidade na compreensão do jogo e apresentaram resultados significativos no pós-teste;

Por meio de observações sobre o decorrer das partidas jogadas e análises qualitativas sobre o pré- e pós-teste, uma análise da aplicação piloto, sob a ótica das habilidades do PC, é reportada na Tabela 1. O grupo azul não demonstrou nenhum comportamento além dos observados também nos outros grupos, portanto as características descritas sobre ele são genéricas e também se aplicam aos demais.

A compreensão das informações descritas no formato de grafos (coleta e análise de dados), desde o pré-teste, foi de uma forma geral bastante satisfatória, o que possibilitou a compreensão do jogo. A dificuldade do grupo amarelo em enxergar o ciclo dos recursos (Figura 1) em contraste com grupo verde, que explicitou a ciência deste ciclo, 
VII Congresso Brasileiro de Informática na Educação (CBIE 2018)

Anais do XXIX Simpósio Brasileiro de Informática na Educação (SBIE 2018)

revela o alto impacto da habilidade de construir algoritmos sobre o jogo. O resultado do pós-teste, em relação ao pré-teste, concorda com desempenho no jogo: grupo azul, sem grandes destaques ou dificuldades no jogo, manteve a nota no teste; grupo amarelo, com muitas dificuldades no jogo, teve uma melhora mínima na nota; e o grupo verde, com bom desempenho no jogo, teve uma melhora significativa na nota.

\section{Conclusão}

Este trabalho apresenta uma análise do jogo educacional "A Última Árvore" sob a perspectiva do PC. É realizada uma breve descrição jogo, suas mecânicas, objetivos e extensões focando nas relações destes com as habilidades do PC. Uma aplicação piloto do jogo, incluindo pré e pós testes também são analisadas sob a ótica do PC. É exposto que existe uma série de relações do jogo com o PC desde sua versão básica, além das relações das GG com o PC. Constata-se que as extensões também apresentam contribuições para o desenvolvimento do PC. É discutido que deficiências ou proficiências em algumas destas habilidades influenciam significativamente no desempenho do aluno no jogo, o que indica forte relação do jogo com tais habilidades. O jogo aborda as habilidades de: Coleta e Análise de dados; Representação de dados; Decomposição de problemas; Abstração; Algoritmos e Procedimentos; Simulação; Paralelismo; Generalização; e Otimização. Em geral, os destaques na versão básica, extensões, análise da aplicação piloto e testes foram: a Coleta e Análise de dados, presente de forma geral e essencial para compreender e operar as GGs, aspecto fundamental do jogo; e Algoritmos e Procedimentos, cruciais para atingir o objetivo do jogo, norteando todas as ações dos jogadores. Como trabalhos futuros, percebe-se a possibilidade de implementação de uma versão digital.

Tabela 1. Análise da aplicação piloto sob a ótica do PC

\begin{tabular}{|c|c|c|c|}
\hline Habilidade & $\overline{A z u l}$ & Amarelo & Verde \\
\hline $\begin{array}{l}\text { Coleta e Análise } \\
\text { de Dados }\end{array}$ & $\begin{array}{l}\text { Foram capazes de compreender o } \\
\text { tabuleiro, as cartas e reconhecê- } \\
\text { los como grafos para aplicar as } \\
\text { regras. Identificaram matches } \\
\text { corretamente na grande maioria } \\
\text { das vezes. Conseguiram entender } \\
\text { os objetivos ilustrados nas cartas. }\end{array}$ & $\begin{array}{l}\text { Apresentaram dificuldades para } \\
\text { compreender as variáveis nas re- } \\
\text { gras. Demoravam consideravel- } \\
\text { mente para encontrar matches, o } \\
\text { que indica dificuldade em reco- } \\
\text { nhecer vértices, arestas e atribu- } \\
\text { tos nos elementos do jogo. }\end{array}$ & $\begin{array}{l}\text { Conseguiram compreender o } \\
\text { jogo por conta própria antes das } \\
\text { explicações básicas, o que indica } \\
\text { compreensão intuitiva do modelo } \\
\text { de gramática de grafos. }\end{array}$ \\
\hline $\begin{array}{l}\text { Representação } \\
\text { de Dados }\end{array}$ & $\begin{array}{l}\text { Conseguiram manusear as car- } \\
\text { tas no tabuleiro para representar } \\
\text { ações descritas por regras corre- } \\
\text { tamente. }\end{array}$ & $\begin{array}{l}\text { Demonstraram incerteza e falta } \\
\text { de confiança ao manusear os ele- } \\
\text { mentos do jogo, mas não chega- } \\
\text { ram a errar aplicações de regras. }\end{array}$ & $\begin{array}{l}\text { Foram confiantes ao manusear as } \\
\text { cartas e fizeram jogadas conside- } \\
\text { ravelmente mais rápidas que os } \\
\text { demais grupos }\end{array}$ \\
\hline $\begin{array}{l}\text { Decomposição } \\
\text { de Problemas }\end{array}$ & $\begin{array}{l}\text { Fragmentaram os objetivos das } \\
\text { cartas sorteadas no início da par- } \\
\text { tida. }\end{array}$ & $\begin{array}{l}\text { Por conta da dificuldade, era } \\
\text { explícito que quebravam os mat- } \\
\text { ches das regras, elemento por ele- } \\
\text { mento. }\end{array}$ & $\begin{array}{l}\text { Nenhuma outra forma } \text { de } \\
\text { decomposição foi percebida } \text { ou } \\
\text { considerada. }\end{array}$ \\
\hline Abstração & \multicolumn{3}{|c|}{$\begin{array}{l}\text { Todos os grupos conseguiram relacionar os conceitos abstratos ilustrados nas regras (tipos de vértices, } \\
\text { arestas e variáveis) aos conceitos concretos no tabuleiro e cartas (vértices, arestas e valores, números). }\end{array}$} \\
\hline $\begin{array}{l}\text { Algoritmos e } \\
\text { Procedimentos }\end{array}$ & $\begin{array}{l}\text { Conseguiram estabelecer planos, } \\
\text { sequências de jogadas. }\end{array}$ & $\begin{array}{l}\text { A maior dificuldade apresentada } \\
\text { pelo grupo, enxergar os passos } \\
\text { necessários para cada recurso. }\end{array}$ & $\begin{array}{l}\text { Identificaram, explicitamente, o } \\
\text { ciclo que é representado na Fi- } \\
\text { gura } 1 .\end{array}$ \\
\hline Simulação & $\begin{array}{l}\text { Assimilaram o jogo ao sistema } \\
\text { que ele simula, uma floresta em } \\
\text { expansão. }\end{array}$ & $\begin{array}{l}\text { Apontaram eventos que não são } \\
\text { simuladas pelo jogo, como su- } \\
\text { bir numa árvore, discutindo as } \\
\text { limitações da simulação. }\end{array}$ & $\begin{array}{l}\text { Discutiram, através da análise do } \\
\text { modelo, sobre o que é possível } \\
\text { acontecer e o que não é, na rea- } \\
\text { lidade simulada pelo jogo. }\end{array}$ \\
\hline Paralelismo & \multicolumn{3}{|c|}{ A concorrência entre os objetivos não foi explicitamente percebida ou considerada. } \\
\hline Generalização & $\begin{array}{l}\text { Identificaram a generalização das } \\
\text { regras. }\end{array}$ & $\begin{array}{l}\text { Nenhuma outra forma } \text { de } \\
\text { generalização foi percebida ou } \\
\text { considerada. }\end{array}$ & $\begin{array}{l}\text { Generalizaram estratégias para } \\
\text { conseguir diferentes recursos }\end{array}$ \\
\hline Otimização & \multicolumn{3}{|c|}{ Nenhuma otimização foi explicitamente percebida ou considerada. } \\
\hline
\end{tabular}


VII Congresso Brasileiro de Informática na Educação (CBIE 2018)

Anais do XXIX Simpósio Brasileiro de Informática na Educação (SBIE 2018)

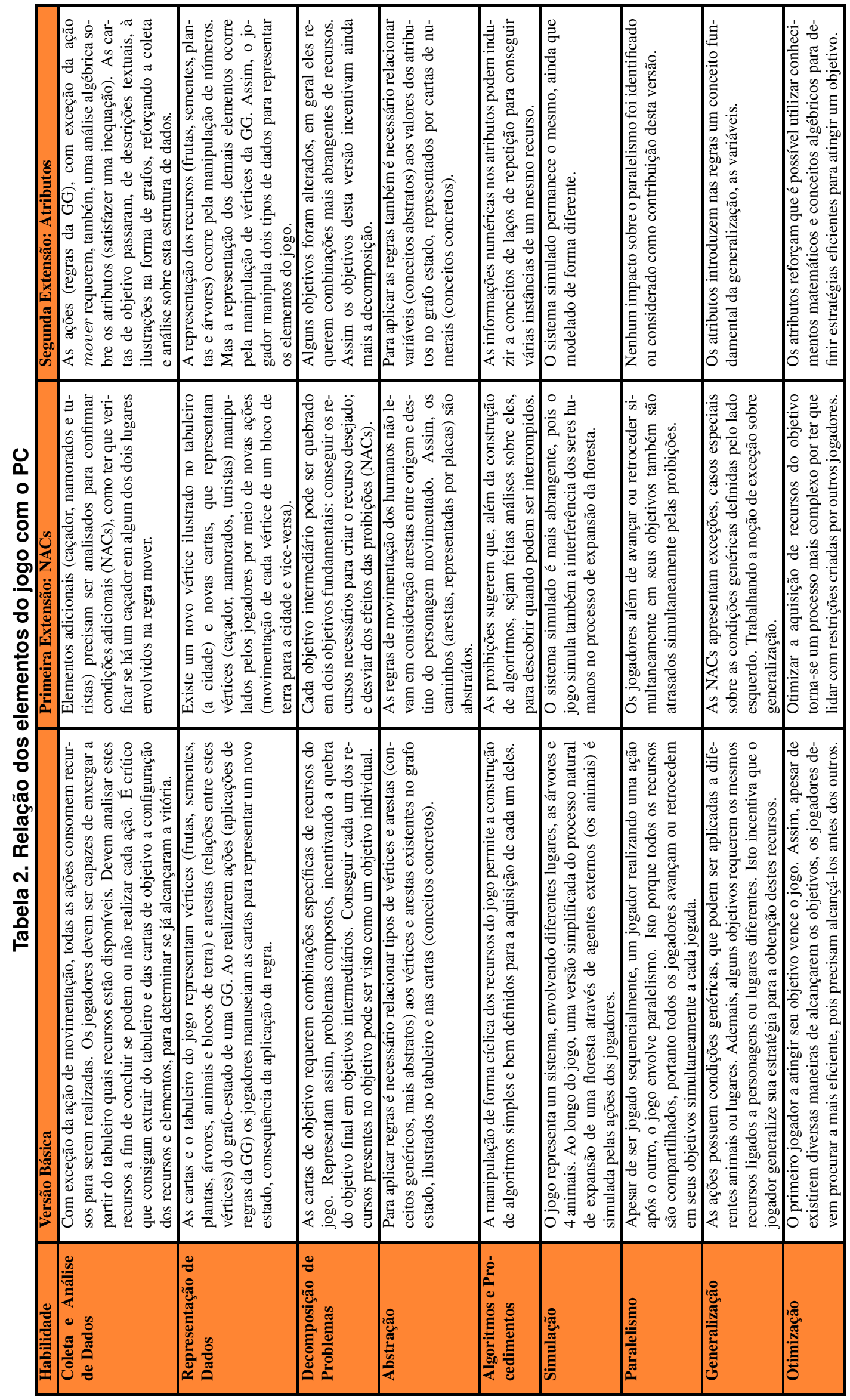


VII Congresso Brasileiro de Informática na Educação (CBIE 2018)

Anais do XXIX Simpósio Brasileiro de Informática na Educação (SBIE 2018)

\section{Referências}

Andrade, D. et al. (2013). Proposta de atividades para o desenvolvimento do pensamento computacional no ensino fundamental. In WIE, pages 169-178.

Avila, C. et al. (2017). O pensamento computacional por meio da robótica no ensino básico - uma revisão sistemática. In SBIE, pages 82-91.

Barr, V. and Stephenson, C. (2011). Bringing computational thinking to k-12: what is involved and what is the role of the computer science education community? Acm Inroads, pages 48-54.

Battistela, P. E., Wangenheim, C. G. v., and Fernandes, J. M. (2014). Como jogos educacionais são desenvolvidos? uma revisão sistemática da literatura. In XXII WEI. SBC.

Battistella, P. E. and von Wangenheim, C. G. (2016). ENgAGED: um processo de desenvolvimento de jogos para ensino em computação. thesis, UFSC. Programa de PósGraduação em Ciência da Computação., Florianópolis, SC, BR.

Bordini, A. et al. (2017). Pensamento computacional nos ensinos fundamental e médio: uma revisão sistemática. In SBIE, pages 123-132.

Brown, N., Kruchten, P., Lim, E., Ozkaya, I., and Nord, R. (2010). The hard choices game explained (whitepaper). Pittsburgh: Software Engineering Institute.

Costella, L. et al. (2017). Construção de ambiente de ensino de robótica remota: democratizando o desenvolvimento do pensamento computacional em alunos da educação básica. In SBIE, pages 354-363.

CSTA, ISTE, and NSF (2009). Computational Thinking Leadership Toolkit. CSTA, Albany, NY, USA.

Garris, R., Ahlers, R., and Driskell, J. E. (2002). Games, motivation, and learning: A research and practice model. Simulation \& gaming, 33(4):441-467.

Nakamura, J. and Csikszentmihalyi, M. (2009). Flow theory and research. Handbook of positive psychology, pages 195-206.

Pessoa, F. I. R. et al. (2017). T-mind: um aplicativo gamificado para estímulo ao desenvolvimento de habilidades do pensamento computacional. In SBIE, pages 645-654.

Pinho, G. et al. (2016). Proposta de jogo digital para dispositivos móveis: Desenvolvendo habilidades do pensamento computacional. In SBIE, pages 100-109.

Ribeiro, L. (2000). Métodos formais de especificação: gramáticas de grafos. VIII Escola de Informática da SBC-Sul, pages 1-33.

Silva Junior, B. A. et al. (2017a). A última árvore: exercitando o pensamento computacional por meio de um jogo educacional baseado em gramática de grafos. In SBIE, volume 28 , pages $735-744$.

Silva Junior, B. A. et al. (2017b). A última árvore: O povo da cidade, utilizando a condição negativa de aplicação em um jogo. In WEIT, volume 4, pages 144-151.

Wing, J. M. (2006). Computational thinking. Communications of the ACM, 49(3):33-35. 